\title{
A Canvas Learning Management System Proposal for Accreditation Reporting Using Rubrics and Assignments
}

\author{
Ian Shepherd \\ Abilene Christian University \\ Don Pope \\ Abilene Christian University \\ Brent Reeves \\ Abilene Christian University
}

Institutions of higher education are increasingly required to document enhancements in the pedagogical arena. Accreditation requirements include the systematic establishment of program and student learning outcomes and assessment of the attainment of these. This process has been labor-intensive and inconsistent for most institutions. Our process is an efficient method for any institution to create and measure the attainment of program and student learning objectives. By setting up assignments and rubrics within the Canvas Learning Management System with a simple prefix tag (standardized for each school for program and student learning objectives), we can automatically report each of the accreditation-related measurements and analyze the results.

Keywords: Canvas, Learning Management System, Accreditation, Reporting, Rubrics, Assignments, Student Learning Objectives, Student Learning Outcomes, Performance Enhancements, Documented Improvements, Pedagogical Tracking, Program Learning Outcomes, Automated Performance Reporting, Performance Related Measurements, Consistent Reporting, Data Accumulation, Data Analyzed, Performance Trajectory, Data Extract, Pivot Data, Assurance of Learning, Systematic, Continuous Improvement, Closed Loop Reporting, Quality Improvement, SACSCOC, AACSB, SACS

\section{INTRODUCTION OF CONCEPT}

Colleges and universities are required to document performance enhancements or improvements in the pedagogical arena to respond to the increasing scrutiny of state legislatures and accrediting organizations. Accreditation requirements include the systematic establishment of program and student learning outcomes and assessment of the attainment of these. The data collection and reporting effort at the individual instructor level has been a barrier to engagement in continuous improvement. Our proposed process is an efficient method for any institution to create and measure the attainment of program objectives and student learning objectives. By setting up assignments and rubrics within the learning 
management system (LMS) (in our case, the Canvas Learning Management System) with a simple prefix tag (standardized for each school for program objectives and student learning objectives), we can automatically report each of the reported accreditation-related measurements. This methodology is consistent, measurable, and comparable.

\section{METHODOLOGY}

By setting up assignments and rubrics within the Canvas Learning Management System (hereafter referred to as Canvas), or any similar system, with a simple prefix tag (standardized for each school for program objectives (PO's) and student learning objectives (SLO's)), we can automatically report, for accreditation purposes, each of the reported accreditation-related measurements. These results were previously calculated and reported manually. See Appendix 1 for a Sample listing of College Of Business Administration graduate program labels for accreditation reporting.

Benefits of this process are:

1. Reporting is automated and removes the need for back end analysis and manual reporting on the part of each instructor.

2. Reporting is consistent. Each semester we can ensure that the measurements are comparable. There are no semester-to-semester differences in analysis and results due to a failure of the comparison process. (I forgot what I did when calculating last semester). Consistent measurement processes remove personal assessment bias.

3. Accumulation of data over time can be analyzed within or between semesters to gauge trajectory and make corrective actions. You can report daily, weekly, monthly, or within a single semester, on single or all classes to calculate the trajectory of performance measures. Feedback can now be given at the same intervals for intervention purposes where required.

4. Detail level in the analysis can be more profound than currently reported. Analysis down to the assignment rubric line level rather than class level is possible (typically a final grade assessment). This allows for more detailed measures. For example, the writing portions of each assignment can be measured against the related objective - e.g., MBA_3.2 from Appendix 1, for every assignment where writing is important (rather than from instructor memory or observation of papers). Topics such as leadership, ethics, human resources, group management, etc., can be assessed in a similar manner.

5. Instructors can be as detailed in their assessment approach (all assignments and all rubric levels in each assignment) or as simple (a few rubric criteria levels included and others ignored) as they feel necessary.

\section{Course Setup}

a. Canvas master courses need to be updated one time with either assignment or rubric criteria level prefix tags using the standardized reporting style for each degree program. Application at the assignment level, e.g., MBA_1.1 Assignment name is illustrated in Figure 1. Application at the rubric criteria level, e.g., MBA_1.1 Rubric criteria, is shown in Figure 2. 
FIGURE 1

\section{ASSIGNMENT LEVEL NAMING CONVENTION}

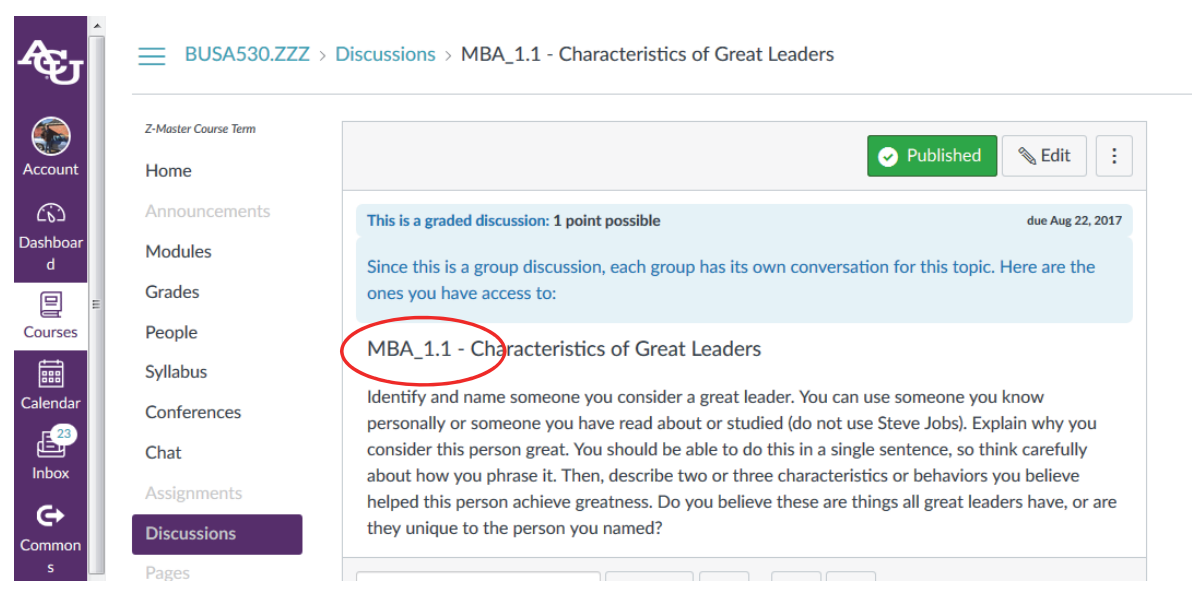

\section{FIGURE 2}

RUBRIC CRITERIA LEVEL NAMING CONVENTION
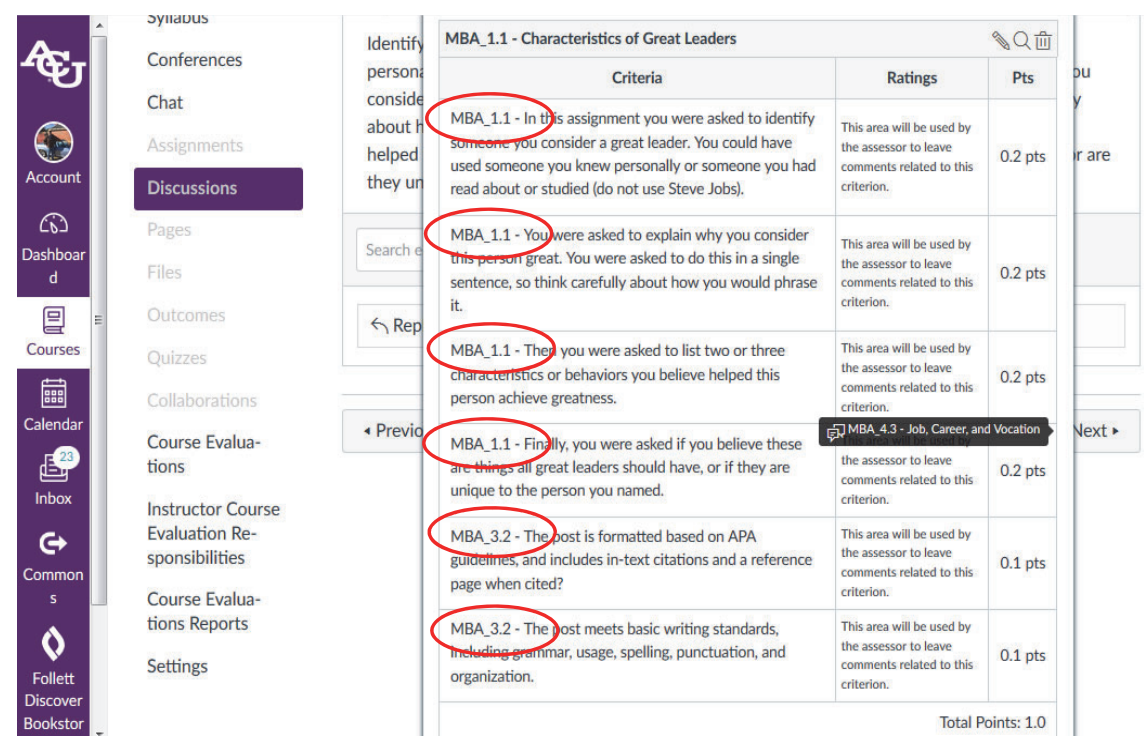

Note: Instructors can be as detailed or simple as they desire. Part of the rubrics can be labeled and other parts not. The reporting system will filter out non-measured items.

b. Standardization of the prefix tags needs to be enforced in key entry (refer to Appendix 1 for our college's codes and measurement topics). Without standardization, the automation of the process becomes impossible. This standardization is critical to consistent measurement.

\section{THE REPORTING SYSTEM}

An extract software application has been developed that polls course data tables created in the background by Canvas (for example, all the MBA classes) and creates comma separated value (CSV) or Excel (XLS) files with all the output data. See Table 1 for the Fields reported. 


\section{TABLE 1}

FIELDS REPORTED

\begin{tabular}{|c|c|c|}
\hline Fields & Output & Description \\
\hline course & 1193 & This is the Canvas Course Number \\
\hline $\operatorname{login}$ & 2674 & This is the Login ID of the Student \\
\hline name & (Student Name Hidden) & This is the Name of the Student \\
\hline asgld & 21069 & This is the Assignment Number in Canvas \\
\hline PO & PO \#2.1 & This is the Performance Objective Number being measured \\
\hline AsgName & Market Prices & This is the Assignment Name in Canvas \\
\hline due & 2018-05-10T04:59:00Z & This is the due date and time. \\
\hline asgPossibles & 2 & This is the maximum number of points possible for the assignment. \\
\hline rubricld & 1837 & This is the rubric number assigned to the assignment. \\
\hline rubricPoints & 0.1 & This is the rubric level maximum points possible \\
\hline points & 0.1 & This is the actual points gained for this rubric level by the student \\
\hline pent & 1 & This is the percent (Points / Rubric Points) \\
\hline SLO & SLO \#3.2 & This is the Student Learning Objective Number being Measured \\
\hline Description & $\begin{array}{c}\text { The post meets basic writing } \\
\text { standards, including grammar, usage, } \\
\text { spelling, punctuation, and } \\
\text { organization. }\end{array}$ & This is the rubric level description being measured. \\
\hline
\end{tabular}

The data table appears as shown in Table 2 as an Excel importable formatted file.

TABLE 2 OUTPUT DATA TABLE

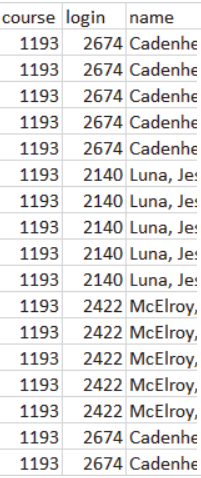

asgld PO AsgName due PO 1.1 Market Price!2018-05-10TC 2_1837 PO \#2.1 Market Prices 2018-05-10TC 2 4900 PO \#2.1 Market Prices 2018-05-10TC 2 _6906 PO \#2.1 Market Prices 2018-05-10T( 2 7703 PO \#2.1 Market Prices 2018-05-10TC 2_9367 PO \#2.1 Market Prices:2018-05-10TC 2_1837 PO \#2.1 Market Prices 2018-05-10TC 2_4900 PO \#2.1 Market Prices 2018-05-10T( 2 2 6906 PO \#2.1 Market Prices 2018-05-10T( 2 7703 PO \#2.1 Market Prices 2018-05-10TC 2_9367 PO \#2.1 Market Prices 2018-05-10TC 2_1837 PO \#2.1 Market Prices 2018-05-10TC 2 4900 PO \#2.1 Market Price: 2018-05-10TC 2 _6906 PO \#2.1 Market Prices 2018-05-10TC 2_7703 PO \#2.1 Market Prices 2018-05-10TC 2_9367 PO \#3.1 Operating Wi2018-05-11Ti 2_3190 $\mathrm{PO} \# 3.1$ Operating Wi 2018-05-11T
rubricPo points pent SLO Description

$\begin{array}{llll}0.1 & 0.1 & 1 & \text { SLO \#3.2 The post meets basic writing standards, including grammar, usage, }\end{array}$ $0.6 \quad 0.50 .833$ SLO \#3.1 How have these behaviors influenced the changes in gas prices?

$\begin{array}{llll}0.1 & 0.1 & 1 & \text { SLO \#3.2 The post is formatted based on APA guidelines, and includes in-text }\end{array}$ $\begin{array}{llll}0.6 & 0.6 & 1 \text { SLO } \# 2.1 \text { How have gas prices changed throughout this past year? }\end{array}$

$\begin{array}{llll}0.6 & 0.6 & 1 & \text { SLO \#2.1 How have the supply and demand of gas been influenced by our bel }\end{array}$

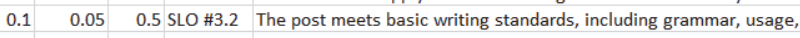
$0.6 \quad 0.50 .833$ SLO \#3.1 How have these behaviors influenced the changes in gas prices?

$0.1 \quad 0.1 \quad 1$ SLO \#3.2 The post is formatted based on APA guidelines, and includes in-text $0.6 \quad 0.6 \quad 1$ SLO \#2.1 How have gas prices changed throughout this past year?

\begin{tabular}{r|r|r|r|r|}
0.6 & 0.6 & 1 & SLO \#2.1 How have gas prices changed throughout this past year? \\
\hline 0.6 & 0.5 & 0.833 SLO \#2.1 & How have the supply and demand of gas been influenced by our bel
\end{tabular} \begin{tabular}{r|r|r|r|r}
0.6 & 0.5 & 0.833 & SLO \#2.1 & How have the supply and demand of gas been influenced by our be \\
\hline .1 & 0.1 & 1 SLO \#3.2 & The post meets basic writing standards, including grammar, usage,
\end{tabular} $0.6 \quad 0.6 \quad 1$ SLO \#3.1 How have these behaviors influenced the changes in gas prices? $0.10 .1 \quad 1$ SLO \#3.2 The post is formatted based on APA guidelines, and includes in-text $0.6 \quad 0.6 \quad 1$ SLO \#2.1 How have gas prices changed throughout this past year?

\begin{tabular}{rrrll}
0.6 & 0.6 & 1 SLO \#2.1 & How have gas prices changed throughout this past year? \\
\hline 0.6 & 0.6 & 1 SLO \#2.1 & How have the supply and demand of gas been influenced by our bel
\end{tabular} $\begin{array}{llll}0.4 & 0.4 & 1 & \text { SLO \#3.1 We all operate with limited resources. How do these limits make us }\end{array}$ $0.2 \quad 0.21$ SLO \#3.2 The post is formatted based on APA guidelines, and includes in-text

This output data table can be reported for a class level or any combination of classes. This allows us to run one report for all MBA courses if so desired. Since the extract criteria are definable, reports can be run at the school or college level as well.

Once the data table is created, a simple pivot table is created. See Table 3 - Pivot Data for a class level example.

TABLE 3 PIVOT DATA OUTPUT

\begin{tabular}{c|c|c|c|} 
Row Labels & Average of Percent & Status & Full Description \\
\hline SLO \#1.2 & $94 \%$ & Exceeds & SLO \#1.2 - Students will recognize and work within elements of organizational culture. \\
\hline SLO \#2.1 & $83 \%$ & Meets & SLO \#2.1 - Students will apply strategic tools to position their organizations for a changing marketplace. \\
\hline SLO \#3.1 & $98 \%$ & Exceeds & SLO \#3.1 - Students will utilize organizational practices and tools to collect, analyze, and use data to make decisions across a wide array of topics. \\
\hline SLO \#3.2 & $96 \%$ & Exceeds & SLO \#3.2 - Students will report findings clearly and with appropriate recognition of the findings' limitations. \\
\hline Grand Total & $94 \%$ & &
\end{tabular}


The output data picks up the point value for each rubric level item (at its lowest evaluation point) or at the assignment level, then reports the actual grade compared to the possible grade in point value format. The pivot table allows the user to accumulate points by any value and then report the percent value assigned to each level.

\section{APPLICATION}

This methodology applies to all Canvas courses, so it is useful beyond our College of Business Administration (COBA) and applicable at the University or School level (since institutions tend to use the same LMS across colleges). We believe that the consistency and accuracy of this methodology will dramatically improve the quality of the reporting for accreditation purposes for the Association to Advance Collegiate Schools of Business (AACSB), or the Commission on Colleges of the Southern Association of Colleges and Schools (SACSCOC) at the university level. The initial workload to change the master classes to reflect this process will require some effort. Once done, however, there is no back end effort required on the part of the instructor other than commenting and responding to assessment findings. By editing the master class copy of the LMS class, you ensure that each semester's assessment data creation is consistent.

\section{ACCREDITATION REQUIREMENTS}

Across the accreditation landscape, many specific requirements must be met. AACSB accreditation (AACSB, 2018), for example, focuses on ensuring faculty and student engagement, accelerating the rate of innovation in the learning environment, and amplifying the impact of business education for the students. A vital component of any accreditation is a system for continuous quality improvement.

Self-evaluation is a critical requirement in any review process for any accreditation, but specifically for our situation, AACSB. The AACSB accreditation process requires these types of review every five years. As part of this process, standard 8 (AACSB, 2018) specifies that there needs to be an assurance of learning in place to gauge the impact of the program in place. This process must be systematic and measurable. Standard 8 reads as follows:

"The assurance of learning process is designed to ensure systematic, continuous improvement of curriculum. Peer review teams will seek evidence that shows learning goals for each degree program are in place. Generally, some commonly observed best practices of mature assurance of learning programs include four to eight learning goals for each degree program and assessment of the objectives related to each learning goal twice and closing the loop once during the review cycle.

Closing the loop is defined as making appropriate changes in the curriculum based on assessment results. Results of the assessment should be documented and available for peer review teams upon request. The assessment processes and results should lead to documented continuous improvement in curriculum." (AACSB, 2018)

Thus the common goals of the initiative are that:

a. It is systematic

b. It is continuous

c. It measures standard learning goals

d. It measures at least twice during a measurement cycle.

e. It allows the loop to be closed by changing the curriculum based on these results

f. It will enable documentation of this improvement. 
Identification of stakeholder requirements, implementation of processes to meet those requirements, assessment, and appropriate corrective action (also known as "closing the loop") are fundamental to any effective quality management system in any context. In the context of higher education, assessment of student learning is a key aspect of the overall Deming quality management "plan-do-check-act" continuous improvement cycle as illustrated in Figure 3.

\section{FIGURE 3 \\ PLAN-DO-CHECK-ACT CONTINUOUS IMPROVEMENT CYCLE IN THE CONTEXT OF HIGHER EDUCATION}

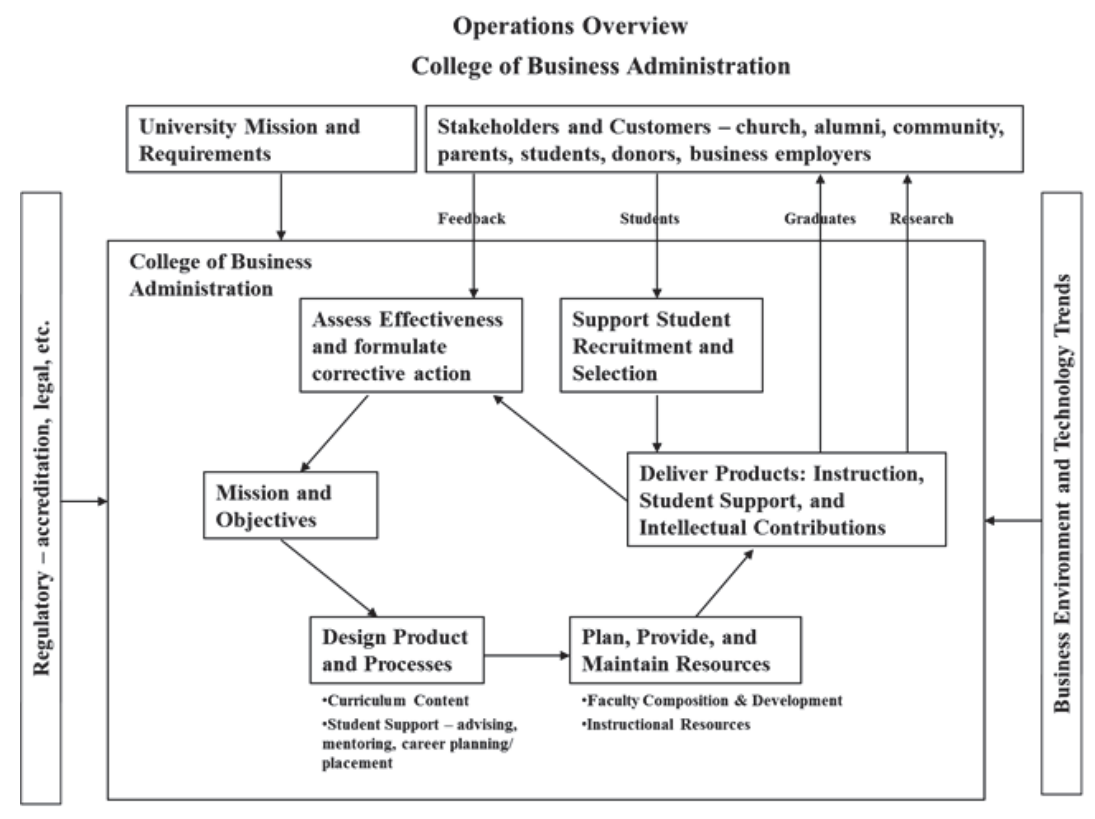

Figure 4 illustrates the key questions and sources of answers in identifying desired learning outcomes, implementing academic processes to support those goals, and measuring the actual level of attainment of those goals. 


\section{FIGURE 4 \\ KEY QUESTIONS AND SOURCES OF ANSWERS IN THE IDENTIFICATION AND ASSESSMENT OF LEARNING OUTCOMES}

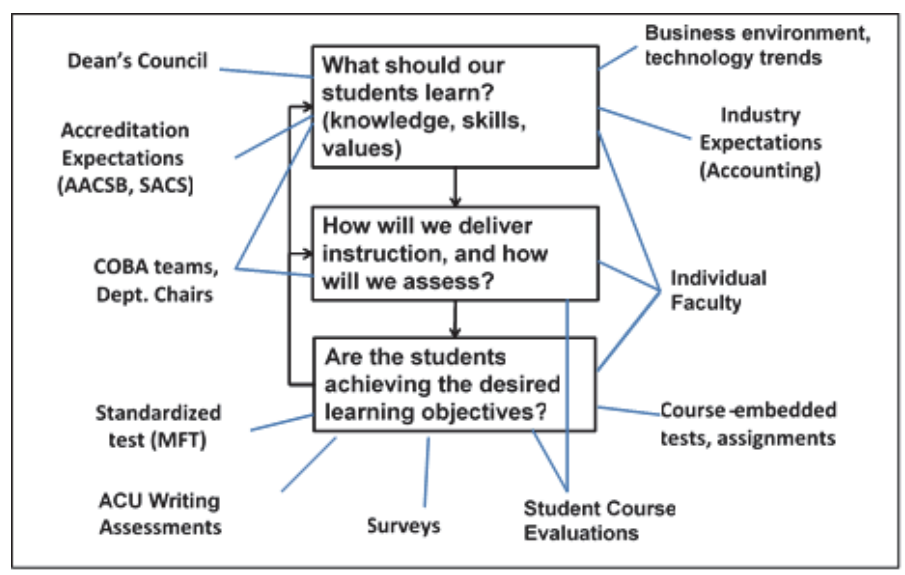

The identification of learning outcome goals, assessment of results, and response to the findings is a fundamental element in accreditation standards. In the Section 8 standard on student achievement, the SACSCOC (SACSCOC, 2018) notes that;

"Student learning and student success are at the core of the mission of all institutions of higher learning. Effective institutions focus on the design and improvement of educational experiences to enhance student learning and support student learning outcomes for its educational programs. To meet the goals of educational programs, an institution provides appropriate academic and student services to support student success."

The specific requirements include the following related to the establishment, assessment, and response to results concerning the attainment of learning outcomes:

- The institution identifies, evaluates, and publishes goals and outcomes for student achievement appropriate to the institution's mission, the nature of the students it serves, and the kinds of programs offered. The institution uses multiple measures to document student success.

- The institution identifies expected outcomes, assesses the extent to which it achieves these outcomes, and provides evidence of seeking improvement based on analysis of the results.

The AACSB (AACSB, 2018) standards section on Teaching and Learning includes the following expectation

"High-quality business schools have processes for determining for each degree program, learning goals that are relevant and appropriate, as well as for designing and delivering curricula to maximize the potential for achieving the expected outcomes. Subsequently, these schools have systems in place to assess whether learning goals have been met. If learning goals are not met, these schools have processes in place to improve."

Standard 8 in this section specifically states that: 
"The school uses well-documented, systematic processes for determining and revising degree program learning goals; designing, delivering, and improving degree program curricula to achieve learning goals; and demonstrating that degree program learning goals have been met."

An effective assurance of learning system must provide a systematic approach for course instructors to collect data and report evaluations (rubric-based skill level evaluations, applicable grades, etc.) for assignments or exams, which directly relate to each learning outcome. Besides numerical feedback, instructors should also provide comments on any issues observed. The college must then evaluate the assessment results and formulate improvement plans as needed, either at the course level or a higher programmatic level.

\section{LITERATURE SEARCH}

There is a vast literature in the education field concerning learning assessment. Nichols (1995) provides guidance for the department tasked by the university to oversee and foster outcomes assessment and institutional effectiveness processes around campus, while Nichols and Nichols (2000) provide implementation guidelines and examples for several different types of academic departments as well as non-teaching support organizations on campus. Lawson et al. (2013) provide a survey of current and best practices in curriculum mapping and data collection related to learning assessment of several different types of academic programs in Australia. Gilbreath et al. (2016) provide a summary of helpful tools for facilitating learning assessment, including assessment plans, curriculum maps, assessment schedules, artifact collection, faculty engagement maps, artifact review procedures, and dashboards. Govindarajulu and Murphy (2017) describe the application of a six sigma problem-solving methodology to improve assurance of learning processes and the resulting implementation of an internally developed database and user interface system.

Concerning business programs in particular, Martell and Calderon (2005) provide a compilation of articles describing best practices for various types of majors within business. Martell (2007) later surveyed several business schools about the state of learning assessment practice, particularly in light of changes in AACSB standards. In April 2003, standards regarding accreditation from AACSB had changed. Under the revised 2003 standards, students had to demonstrate learning achievement; thus, the focus shifted from what teachers taught to what students learned. The survey results showed that among other factors, the increased time and effort required for assessment was a major concern. Pringle and Michel (2007) and Garrison and Rexeisen (2014) also surveyed several business schools about factors impacting faculty engagement in assessment processes, and the amount of faculty and assessment coordinator effort involved is a common denominator in the survey responses. De'Armond and Patterson (2018) present a process used to collect the entirety of the assessment data needed within an MBA program. The process includes the collection of both indirect reflective student data from an MBA portfolio course along with more direct objective data from faculty assessments of student work.

Common denominators in all of the literature are the need to ease and systematize data collection to ensure the sustainability of the assessment process. The proposed methodology in this paper addresses these requirements as follows:

a. It is programmatically organized to ensure comparability of output and process.

b. The software application can be run on a scheduled or ad-hoc basis.

c. The software application uses standardized "tags" linking learning objectives at the university, school, department, class, student, assignment and rubric criteria levels.

d. The software application should be executed at least once during each semester, usually at the final grading period. If the cycle is run each semester within a five-year measurement cycle, there are at least ten data points for objective measurement and analysis. Summer sessions or non-traditional semester cycles are handled along the same reporting methods.

Journal of Higher Education Theory and Practice Vol. 19(4) 2019109 
Proactive instructors can use this process to measure within each semester how the class or students measure on the performance objectives scale.

e. By using comparable tag codes, each coded objective can be compared across or within measurement cycles.

f. Data storage and archives allow outputs to be stored across measurement cycles. With LMS classes being archived each year, the system also provides for data cycles to be re-examined should there be a need to re-measure or re-code objectives for proof of improvement. Accumulation of data thus allows for a single measurement of any number of years of data for each learning objective.

\section{QUESTIONS AND ANSWERS}

1. Question: Why not use Canvas' Learning Outcomes? Answer: You can! An outcome can be selected using the rubric creation so that each assignment can have both assignment level/rubric level notation and overall outcome level. You can be as detailed or simple as you want to be. You can measure three rubric levels of grading out of 6 and then an overall learning objective level as well.

2. Question: Why do we have to have a special extract program? Answer: Because the Canvas grades extract does not export line item details for rubrics, just the overall grade at the assignment level. The specialized extract program operates at a lower level. We are using the Canvas REST API via a python script to output the raw data for excel reporting and analysis.

3. Question: What about the university's Information Technology Department (IT) involvement? Answer: Either IT, or local departments, or colleges could run these reports on an ad hoc or scheduled basis for analysis and trajectory of performance measurements.

4. Question: What about Privacy/Security issues? Answer: The output file has student level identifiable grade data. Access and security requirements are no different than current university requirements. IT could run nightly data runs and post the reporting output to various accounts as required.

5. Question: what about one department/college seeing another department/college data? Answer: Access through reporting has the same security requirements as currently used. Access depends on the level given now to any professor, dean or administrator.

\section{PROCESSING EXTRACTS - REST METHODOLOGY}

There are two reasons for using Canvas' REST. First, the usual teacher or administrator interface to a Canvas course does not allow a user to export the results of a rubric at the lowest level. Only the overall grade is reported. Second, for our process, we needed to run extracts for a few hundred courses (all Canvas courses at our institution), and it was convenient to write our processing loop to process each of the courses we were including.

The main segments of processing logic are as follows.

- Canvas' REST Application Programmer Interface (API) requires a program to provide an authentication token. This token can be per course, in which case a teacher could generate the token. However, the token can also be for an entire account, which we used in this case.

- Since our end-goal was to extract everything relevant to accreditation, we needed a way to identify those assignments. We chose to tag relevant assignments with prefixes as shown in Appendix 1. This required the teacher to update current assignments in their Canvas Master Course. 
- The data we needed was at the intersection of course, assignment, and rubric. The simplest way to combine the data from these three places was not to do it in an extract program, but rather to populate database tables, and then write SQL queries that do the appropriate merging. We used the sqlite3 package suitable for python.

- Code examples are given in appendices, but the main loop looks like this for each course in our account:

a) extract assignments starting with $\mathrm{PO}, \mathrm{SLO}$, or MBA

b) keep fields such as id, name, due at, points, etc.

c) extract submissions including 'rubric assessments'

d) keep fields such as user, assignment-id, points, etc.

e) finally, run a query that joins assignment, rubric, and scores to produce a Comma Separated Values (CSV) file

\section{OUTPUT EXAMPLES}

Figure 5 shows the first few rows of a CSV file containing entries from two students. It conforms to common CSV conventions so that it can be imported by usual programs such as Excel.

Output fields reported are: course id, login it, student name, assignment id, assignment accreditation flags, assignment name, due date, possible points, rubric id, rubric points, earned points, percent, detailed accreditation flag, detailed rubric description.

\section{FIGURE 5}

OUTPUT EXAMPLE

1318,3103,"Student1",27208,MBA,2.1,MBA 2.1,- Market Prices,2018-10-

25T04:59:00Z,2.0,_1837,0.1,0.1,1.0,MBA 3.2,"- The post meets basic writing standards, including grammar, usage, spelling, punctuation, and organization."

1318,3103,"Student1",27208,MBA,2.1,MBA 2.1,- Market Prices,2018-10-

25T04:59:00Z,2.0,_4900,0.6,0.6,1.0,MBA 3.1,- How have these behaviors influenced the changes in gas prices?

1318,3103,"Student1",27208,MBA,2.1,MBA 2.1,- Market Prices,2018-1025T04:59:00Z,2.0,_6906,0.1,0.05,0.5,MBA 3.2,"- The post is formatted based on APA guidelines, and includes in-text citations and a reference page when cited?"

\section{LMS - IMPLICATIONS OR POSSIBLE INCLUSIONS.}

The reader may wonder why we do not just run queries directly against a Canvas Data instance. First, our institution was not familiar enough with Canvas Data to judge whether it was possible. Second, since we already had experience with the REST API for other extract purposes, it was not difficult to execute this solution. We are exploring the possibilities of using Canvas Data in the future.

\section{PROCESSING NOTES}

As you can see, the REST API is certainly suitable for extracting detailed and specific information from an entire account. However, there are a few catches for the new user.

As mentioned above, one must obtain an authentication token, and this step must be done correctly. A token looks something like the string displayed in Figure 6. 


\section{FIGURE 6}

\section{A REST API TOKEN}

\section{'Bearer 8431 K39xkN9eq...02Tr187730wnvWjh43'}

Another surprise for the programmer is that a web request does not behave exactly like a database query. When processing the result of a SQL query, one comes to expect the following to work:

- run a query

- for each row in the query result:

- do something with fields in that row

But a web request has the added complexity of being possibly paginated. So one must factor in a slightly more cumbersome method:

- run a web request

- for each row in the result:

- do something with the fields in that row

- if there are more pages to fetch, continue to fetch-and-process

The reason this approach is necessary is that the Canvas server may limit output to $\mathrm{X}$ results and does so by indicating in the result, whether there are more "pages." An example of the code that can be used to create the required output can be requested from the authors.

\section{CONCLUSION}

An effective assurance of learning system must provide a systematic approach for course instructors to collect results and report evaluations (rubric-based skill level evaluations, applicable grades, etc.) for assignments or exams, which directly relate to each learning outcome. The key descriptors of the proposed process are "systematic" or "consistent." Another key feature of the process is its adaptable level of detail of data collection and reporting as needed. Using this process now allows the college or instructor to devote less time to data collection and metrics computation and focus instead on evaluation of the assessment results and formulate improvement plans as needed, either at the course level or a higher programmatic level. 


\section{REFERENCES}

AACSB Accreditation Standards Overview. (2018). Retrieved from https://www.aacsb.edu/accreditation/standards

AACSB, (2018). Retrieved from https://www.aacsb.edu//media/aacsb/docs/accreditation/business/standards-and-tables/2018-businessstandards.ashx?la $=\mathrm{en}$

De'Armond, D., \& Patterson, R. (2018). Assurance of learning at the graduate level: An innovative roadmap for MBA program assessment. Research in Higher Education Journal, 35. Retrieved from https://eric.ed.gov/?id=EJ1194411

Garrison, M. J., \& Rexeisen, R. J. (2014). Faculty ownership of the assurance of learning process: Determinants of faculty engagement and continuing challenges. Journal of Education for Business, 89(2), 84-89.

Gilbreath, B., Norman, S. M., Frew, E. J., Fowler, K. L., \& Billington, P. (2016). Helpful tools for managing the assurance of learning process. Business Education Innovation Journal, 8(1), 111122. Retrieved January 4, 2019, from http://ezproxy.acu.edu:2052/login.aspx?direct=true\&AuthType $=$ sso \&db=bth\&AN=117612849\&s ite $=$ eds-live $\&$ scope $=$ site $\&$ custid $=$ s 8479690

Govindarajulu, C., \& Murphy, J. (2017). Improving the assessment (assurance of learning) processes. Communications of the IIMA, 15(3), 1-21. Retrieved from http://ezproxy.acu.edu:2052/login.aspx?direct $=$ true\&AuthType $=$ sso $\& \mathrm{db}=\mathrm{aci} \& \mathrm{AN}=130613848 \& \mathrm{~s}$ ite $=$ eds-live \&scope $=$ site \&custid $=$ s 8479690

Lawson, R., Taylor, T., Fallshaw, E., Summers, J., Kinash, S., French, E., \& Angus-Leppan, T. (2013). Hunters and gatherers: Strategies for curriculum mapping and data collection for assuring learning.

Martell, K. (2007). Assessing student learning: Are business schools making the grade? Journal of Education for Business, 82(4), 189-195.

Martell, K. D., \& Calderon, T. G. (Eds.). (2005). Assessment of student learning in business schools: Best practices each step of the way (1). Tallahassee, FL: Association for Institutional Research.

Nichols, J. O. (1995). A practitioner's handbook for institutional effectiveness and student outcomes assessment implementation. Agathon Press, 100 Newfield Avenue, Edison, NJ 08837.

Nichols, J. O., \& Nichols, K. W. (2000). The departmental guide and record book for student outcomes assessment and institutional effectiveness. Agathon Press, 100 Newfield Avenue, Edison, NJ 08837.

Pringle, C., \& Michel, M. (2007). Assessment practices in AACSB-accredited business schools. Journal of Education for Business, 82(4), 202-211.

Rubin, R. S., \& Martell, K. (2009). Assessment and accreditation in business schools. The Sage handbook of management learning, education, and development, 364-383.

SACSCOC. (2017). Retrieved September 30, 2018, from http://www.sacscoc.org/pdf/2018PrinciplesOfAcreditation.pdf 


\section{APPENDIX 1 \\ SAMPLE LISTING OF COLLEGE OF BUSINESS ADMINISTRATION GRADUATE PROGRAM LABELS FOR ACCREDITATION REPORTING}

\begin{tabular}{|c|l|}
\hline Code & \multicolumn{1}{c|}{ Description } \\
\hline MBA_1.0 & $\begin{array}{l}\text { Students will practice effective leadership of themselves, their teams, their } \\
\text { organizations, and their external constituents. }\end{array}$ \\
\hline MBA_1.1 & $\begin{array}{l}\text { Students will understand leadership processes and develop a personal leadership } \\
\text { approach. }\end{array}$ \\
\hline MBA_1.2 & Students will recognize and work within elements of organizational culture. \\
\hline MBA_1.3 & $\begin{array}{l}\text { Students will employ teams and cooperative efforts inside and outside organizations to } \\
\text { achieve desired outcomes. }\end{array}$ \\
\hline MBA_2.0 & $\begin{array}{l}\text { Students will lead organizational innovation efforts through effective integration of } \\
\text { strategy with appropriate organizational processes and technologies. }\end{array}$ \\
\hline MBA_2.1 & $\begin{array}{l}\text { Students will apply strategic tools to position their organizations for a changing } \\
\text { marketplace. }\end{array}$ \\
\hline MBA_2.2 & $\begin{array}{l}\text { Students will design and deploy organizational processes and technologies to improve } \\
\text { organizational performance. }\end{array}$ \\
\hline MBA_3.0 & Students will engage in data-informed decision making. \\
\hline MBA_3.1 & $\begin{array}{l}\text { Students will utilize organizational practices and tools to collect, analyze, and use data } \\
\text { to make decisions across a wide array of topics. }\end{array}$ \\
\hline MBA_3.2 & $\begin{array}{l}\text { Students will report findings clearly and with appropriate recognition of the findings' } \\
\text { limitations. }\end{array}$ \\
\hline MBA_4.0 & $\begin{array}{l}\text { Students will make ethical decisions informed by values and goals that are consistent } \\
\text { with relevant laws and Christian principles. }\end{array}$ \\
\hline MBA_4.1 & Students will understand fundamental principles of business law in the United States. \\
\hline MBA_4.2 & $\begin{array}{l}\text { Students will understand and apply their personal ethical framework to business } \\
\text { decisions. }\end{array}$ \\
\hline MBA_4.3 & Students will reflect on their vocation in the context of their personal values and goals. \\
\hline
\end{tabular}

